\title{
Relationship between Postmenopausal Vitamin D Level, Menopausal Symptoms and Sexual Functions
}

\author{
Meryem Askin1, Esra Meltem Koc1, Mustafa Soyoz², Saliha Aksun³, Serpil Aydogmus 4 and Kaan Sozmen 5 \\ Department of Family Medicine1 / Medical Biology2 / Medical Biochemistry ${ }^{3}$ /Gynecology and Obstetrics ${ }^{4} /$ Public Health $^{5}$, \\ Faculty of Medicine, Katip Celebi University, Izmir, Turkey
}

\begin{abstract}
Objective: To determine whether vitamin $D$ levels correlate with menopausal symptoms and female sexual functions. Study Design: A cross-sectional study.

Place and Duration of Study: Izmir Katip Celebi University Hospital, Izmir, Turkey, between February and October 2017. Methodology: Menopausal and sexual active ladies aged 40-70 years were inducted. Those with psychiatric disorders, endocive abnormalities, related therapy, and malignancy were excluded. Menopause Rating Scale (MRS), and the Female Sexual Function Index ( $F S F I)$ were used to collect data. Also blood samples were collected from the patients. The study's data were examined with logistic and linear regression models.

Results: Total MRS scale scores of the 303 subjects with one of the following conditions had a higher menopause symptom score; chronic disease, vaginal discharge, chronic pain, unsatisfied with sex, sleep problems, and low vitamin $D$ level $(p=0.023, p=0.007, p<0.001, p<0.001, p=0.017$, and $p<0.001$; respectively). It was found that those who have middle income level were more likely to have better sexual function (OR: $0.209,95 \% \mathrm{Cl}: 0.065 ; 0.671)$ compared to those who have low income level. It was found that those with higher MRS somatic complaint (OR: $1.274 ; 95 \% \mathrm{Cl}: 1.087 ; 1.494)$ and urogenital complaint (OR: 1.670; $95 \% \mathrm{Cl}$ : 1.326; 2.102) and ones with lower vitamin D levels (OR: 0.963; \%95 Cl: 0.941; 0.987 ) were more likely to report complaints for sexual function disorders.

Conclusion: Vitamin D of all women in menopause should be evaluated. High vitamin D levels should reduce menopausal symptoms and positively affect sexual function.
\end{abstract}

Key Words: Menopausal symptom, Sexual function, Vitamin D.

How to cite this article: Askin M, Koc EM, Soyoz M, Aksun S, Aydogmus S, Sozmen K. Relationship between postmenopausal vitamin D level, menopausal symptoms and sexual functions. J Coll Physicians Surg Pak 2019; 29(9):823-7.

\section{INTRODUCTION}

Menopause is the absence of menstrual bleeding in relation to the loss of ovarian activity. ${ }^{1}$ Together with a decline in estrogen, menopausal women experience physical, hormonal, and psychological changes.1,2 Approximately $80 \%$ of menopausal women experience menopause-related symptoms. ${ }^{1}$

Vitamin $D$ deficiency is more frequently observed during menopause due to decrease in the 7-dehydrocholesterol levels in the skin; the increase in the amount of fat in the body; the decrease of the bioavailability of vitamin $D$, which is a fat-soluble vitamin; and a decrease in the $1-\alpha$-hydroxylase activity in the kidney. ${ }^{3}$

The sexual function disorders commonly seen in women can worsen with the decrease of androgens during postmenopausal period. ${ }^{4}$ The limited number of studies

Correspondence to: Dr. Meryem Askin, Department of Family Medicine, Faculty of Medicine, Katip Celebi University, Basin Site, 35160 Karabaglar, Izmir, Turkey

E-mail: obgndrmeryem@hotmail.com

Received: February 08, 2019; Revised: April 26, 2019;

Accepted: May 30, 2019 reported that vitamin $D$ decreases hot flashes by preserving the level of serotonin, which is an effective neurotransmitter over thermoregulation; increases the blood flow of sexual organs during sexual relations by increasing the production of nitric oxide; increases the production of hormones associated with testosterone and because it decreases the frequency of depression with receptors found in regions of depression like the thalamus and hypothalamus in the brain, it can positively affect sexual function. ${ }^{3-5}$

Vitamin $D$ has been shown experimentally to provide protection against the reduction of serotonin, which is effective on thermoregulation. ${ }^{5}$ Therefore, vitamin $D$ may be used in the treatment of vasomotor symptoms in menopausal women. 5

The decrease in the sexual function of menopausal women affects their lives negatively, and considering the serious side effects of the drugs used for treatment, alternative therapies are needed to improve sexual function in the menopausal period. 4

The aim of this study was to investigate the effect of vitamin $D$ levels on sexual functions and menopausal symptoms. 


\section{METHODOLOGY}

This cross-sectional study was carried out at the Izmir Katip Celebi University Hospital between February and October 2017. The ethical approval of this study was received with decision No.155 (date 17.11.2016) from the Izmir Katip Celebi University, Faculty of Medicine, Clinical Research Ethics Committee. Considering previous studies, when patients were divided into 3 groups based on vitamin D deficiency, the goal was to include 303 individuals in the study for a $90 \%$ strong and $5 \%$ error, 0.4 difference, and 0.9 standard deviation in the lubrication subscale scores of the Female Sexual Function Index (FSFI). 6

Inclusion criteria were women in menopause (no menstrual bleeding in the past 12 months or had bilateral salpingooophorectomy), 40-70 years of age, and sexually active in the past four weeks. Exclusion criteria were psychiatric disease, hypothyroidism or hyperthyroidism, malignancy or medication (hormone replacement treatment, lubricant/ vaginal estrogen, or vitamin $D$ intake in the last 3 months).

Data collection instruments included menopause rating scale (MRS) consists of 11 items from 3 sub-dimensions that assess somatic, psychological, and urogenital complaints and adapted in Turkish by Gurkan. ${ }^{7}$ The total points of the scale are calculated based on the points provided for each item. The lowest score that can be obtained from the scale is 0 and the highest is 44 . FSFI is a Likert type scale composed of 19 items and adapted in Turkish. 8 The scale consists of six separate headings (desire, arousal, lubrication, orgasm, satisfaction, and pain). Each item received scores between 0 or 1 and 5 . The lowest score that can be received from the scale was 2 and the highest was 36 . Individuals with a total FSFI score lower than 26.55 were considered as having a sexual dysfunction, and a score above 26.55 demonstrates normal sexual function. ${ }^{6}$

25-Hydroxy Vitamin [D25(OH)D3] was used to determine the level of vitamin $D$ because it had a long half-life. Less than $20 \mathrm{ng} / \mathrm{mL}$ D25(OH)D3 was defined as deficiency, 20-30 ng/mL D25(OH)D3 was defined as insufficiency and higher than $30 \mathrm{ng} / \mathrm{mL}$ D25(OH)D3 was defined as sufficient. Patients with a TSH value of more than 4 $\mathrm{mU} / \mathrm{L}$ and less than $0.5 \mathrm{mU} / \mathrm{L}$ were excluded from the study. Vitamin D and TSH levels were measured with chemiluminescence microparticle immunoassay (CMIA) method in Advia Centaur XP (Siemens, Germany) device.

Statistical analyses were conducted by using the SPSS version 16.0. Normal distribution of variables was measured by Kolmogorov-Smirnov test. Statistical differences between categorical variables were evaluated using Chi-square test. Three group comparisons were assessed by using one-way ANOVA. Independent effects over the sexual functions and menopausal symptoms of the different identifying factors were examined with logistic and linear regression models. The variables with $p \leq 0.10$ were included to the multivariable linear regression model with a "Backward"
Table I: Sociodemographic characteristics and vitamin D value of women participating in the study.

\begin{tabular}{|c|c|c|c|}
\hline Variables & \begin{tabular}{|c|} 
Sexual dysfunction \\
$\mathrm{n}(\%)$ \\
\end{tabular} & $\begin{array}{c}\text { Normal sexual } \\
\text { function } \\
\mathrm{n}(\%)\end{array}$ & $p$-value \\
\hline \multicolumn{4}{|l|}{ Age } \\
\hline $40-50$ & $64(27.5)$ & $21(30)$ & \\
\hline $51-60$ & $127(54.5)$ & $47(67.1)$ & 0.006 \\
\hline $61-70$ & $42(18)$ & $2(2.9)$ & \\
\hline \multicolumn{4}{|l|}{ Body mass index (BMI) } \\
\hline Normal (18.5-24.5) & $36(15.5)$ & $30(42.9)$ & \\
\hline Overweight $(25-29,9)$ & $87(37.3)$ & $29(41.4)$ & $<0.001$ \\
\hline Obese (30-40) & $110(47.2)$ & $11(15.7)$ & \\
\hline \multicolumn{4}{|l|}{ Educational status } \\
\hline Primary school and lower & $165(70.8)$ & $29(41.4)$ & \\
\hline Middle school and high school & $46(19.7)$ & $31(44.3)$ & $<0.001$ \\
\hline College & $22(9.4)$ & $10(14.3)$ & \\
\hline \multicolumn{4}{|l|}{ Social security } \\
\hline No & $12(5.2)$ & $2(2.9)$ & 0.534 \\
\hline Yes & $221(94.8)$ & $68(97.1)$ & \\
\hline \multicolumn{4}{|l|}{ Income level } \\
\hline 1500 Turkish liras or below (low) & $78(33.5)$ & $10(14.3)$ & \\
\hline 1501 - 3500 Turkish lira (middle) & $104(44.6)$ & $35(50)$ & 0.004 \\
\hline 3501 Turkish liras or higher (high) & $51(21.9)$ & $25(35.7)$ & \\
\hline \multicolumn{4}{|l|}{ Marital status } \\
\hline Single / separated & $17(7.3)$ & $6(8.6)$ & 0.797 \\
\hline Married / living together & $216(92.7)$ & $64(91.4)$ & \\
\hline \multicolumn{4}{|l|}{ Menopause type } \\
\hline Surgical & $49(21)$ & $13(18.6)$ & 0.737 \\
\hline Natural & $184(79)$ & $57(81.4)$ & \\
\hline \multicolumn{4}{|l|}{ Presence of chronic illness } \\
\hline No & $108(46.4)$ & $34(48.6)$ & 0.786 \\
\hline Yes & $125(53.6)$ & $36(51.4)$ & \\
\hline \multicolumn{4}{|l|}{ Vitamin $D$ value } \\
\hline Deficiency & $180(77.3)$ & $38(54.3)$ & $<0.001$ \\
\hline Insufficiency & $32(13.7)$ & $12(17.1)$ & \\
\hline Sufficient & $21(9)$ & $20(28.6)$ & \\
\hline
\end{tabular}

Table II: Mean FSFI and MRS scores stratified by vitamin D level categories*.

\begin{tabular}{l|c|c|c|c}
\hline \multirow{2}{*}{ Scales } & \multicolumn{3}{|c|}{ Vitamin D level } & $\begin{array}{c}\text { Statistical } \\
\text { analysis }\end{array}$ \\
\cline { 2 - 5 } & $\begin{array}{c}\text { Deficiency } \\
\text { Mean } \pm \text { SD } \\
\text { (Group I) }\end{array}$ & $\begin{array}{c}\text { Insufficiency } \\
\text { Mean } \pm \text { SD } \\
\text { (Group II) }\end{array}$ & $\begin{array}{c}\text { Normal } \\
\text { Mean } \pm \text { SD } \\
\text { (Group III) }\end{array}$ & p-value \\
\hline FSFI & $2,76 \pm 1,00$ & $2,93 \pm 1,05$ & $3,84 \pm 1,13 \mathrm{a}$ & $<0,001$ \\
Sexual desire score & $4,84 \pm 1,64$ & $5,14 \pm 1,89$ & $6,49 \pm 1,51 \mathrm{a}$ & $<0,001$ \\
Arousal score & $1,74 \pm 0,64$ & $1,83 \pm 0,74$ & $2,24 \pm 0,56 \mathrm{a}$ & $<0,001$ \\
Lubrication score & $3,45 \pm 1,23$ & $3,49 \pm 1,31$ & $4,47 \pm 1,01 \mathrm{a}$ & $<0,001$ \\
Orgasm score & $3,50 \pm 1,25$ & $3,71 \pm 1,37$ & $4,53 \pm 1,03 \mathrm{a}$ & $<0,001$ \\
Satisfaction score & $3,33 \pm 1,24$ & $3,52 \pm 1,48$ & $4,50 \pm 1,15 \mathrm{a}$ & $<0,001$ \\
Pain score & $19,64 \pm 6,27$ & $20,65 \pm 7,18$ & $26,11 \pm 5,56 \mathrm{a}$ & $<0,001$ \\
FSFI total scale score & & & & \\
\hline MRS & $6,13 \pm 3,37$ & $6,22 \pm 2,98$ & $4,04 \pm 2,76 \mathrm{~b}$ & 0,001 \\
Somatic subscales & $5,65 \pm 3,32$ & $5,72 \pm 3,10$ & $3,48 \pm 2,72 \mathrm{~b}$ & $<0,001$ \\
Psychological subscales & $4,92 \pm 2,43$ & $4,63 \pm 2,61$ & $2,80 \pm 1,97 \mathrm{~b}$ & $<0,001$ \\
\hline Urogenital subscales & $17,71 \pm 7,68$ & $16,59 \pm 6,77$ & $10,34 \pm 6,22 \mathrm{~b}$ & $<0,001$ \\
\hline Total score &
\end{tabular}

* One-way ANOVA test was used to compare groups

a Group III significantly higher Groupe I've Group II

b Group III significantly lower Groupe I've Group II

$S D=$ Standard deviation 
elimination method. P-value lower than 0.05 was considered statistically significant.

\section{RESULTS}

A total of 307 individuals agreed to participate in the study. Four patients were excluded from the study due to their abnormal TSH values, the study was completed with 303 patients. The mean age of participants was $53.84 \pm 6.17$ years. Prevalence for deficiency of vitamin D was $71.9 \%(n=218$, Table I). The effect of vitamin $D$ levels on FSFI and MRS scores is shown in Table II.

According to linear regression analysis, patients with chronic disease, vaginal discharge, unsatisfied with sex, sleep problems, and low vitamin $D$ level $(p=0.023$, $p=0.007, p<0.001, p<0.001, p=0.017$, and $p<0.001$ respectively) had higher MRS score (Table III).

Logistic regression analysis revealed that those with higher MRS somatic values (OR: 1.274; 95\% Cl: 1.087; 1.494 ) and urogenital values (OR: $1.670 ; 95 \% \mathrm{Cl}: 1.326$; 2.102), and ones with lower vitamin D levels (OR: 0.963;

Table III: Linear regression analysis on menopausal symptoms.

\begin{tabular}{l|c|c|c|c}
\hline \multirow{2}{*}{ Variables } & \multicolumn{2}{|c|}{$95 \% \mathrm{Cl}$} & $\begin{array}{c}\text { Statistical } \\
\text { analysis }\end{array}$ \\
\cline { 3 - 5 } & $\mathrm{B}$ & Lower & Upper & p-value \\
\hline Presence of chronic illness & 1.868 & 0.255 & 3.480 & 0.023 \\
\hline Vaginal discharge & 2.406 & 0.672 & 4.140 & 0.007 \\
\hline Common body pain & 4.068 & 2.318 & 5.818 & $<0.001$ \\
\hline Sexual-life satisfaction & -3.582 & -5.256 & -1.908 & $<0.001$ \\
\hline Sleep duration & -0.604 & -1.098 & -0.110 & 0.017 \\
\hline Vitamin D levels & -0.132 & -0.190 & -0.073 & $<0.001$ \\
\hline
\end{tabular}

$R^{2}: 35.9 ; \quad \beta=$ Regression coefficient.
$\% 95 \mathrm{Cl}: 0.941 ; 0.987)$ were more likely to have sexual function disorders (Table IV).

\section{DISCUSSION}

In this study, the relationship between post-menopausal vitamin D level, menopausal symptoms, and sexual function was evaluated. Individuals with normal vitamin D levels experienced post-menopausal symptoms less severely and had better sexual function. Also chronic disease, vaginal discharge, chronic pain, satisfaction of sex life, and sleep duration effected severity of menopausal symptoms negatively. Individuals with middle income and ones with lower somatic and urogenital complaint scores had a better sexual function score.

In this study, $71.9 \%(n=218)$ of the women had vitamin $D$ deficiency. According to a research conducted in 2013 in Turkey, the vitamin $\mathrm{D}$ deficiency prevalence among menopausal women was reported as $84.8 \% .{ }^{9}$ The discrepancy in prevalence of vitamin $D$ deficiency in this study could be due to higher exposure of individuals to sunlight in Izmir province compared to Ankara, because of their geographical locations, which might have caused lower vitamin $D$ deficiency levels. The prevalence of vitamin $D$ deficiency ranges between $30 \%-80 \%$ in Europe and $30 \%-90 \%$ in Central Asia. 10 The worldwide variation in prevalence of Vitamin $D$ deficiency might be due to differences in laboratory techniques; and some societies might have a genetic predisposition to vitamin $D$ deficiency. ${ }^{10}$ It would be beneficial to conduct studies both in Turkey and across the world to determine region specific cut-off value for vitamin $D$ deficiency.

Table IV: Logistic regression analysis on low sexual function.

\begin{tabular}{|c|c|c|c|c|c|c|}
\hline \multirow[t]{2}{*}{ Determining factors } & \multicolumn{3}{|c|}{ Odds ratio (Univariate) } & \multicolumn{3}{|c|}{ Odds ratio (Multivariate) } \\
\hline & $\beta$ & $95 \% \mathrm{Cl}$ & $\mathrm{p}$-value & B & $\% 95 \mathrm{Cl}$ & p-value \\
\hline Age & 0.948 & $0.905 ; 0.993$ & 0.025 & 0.926 & $0.837 ; 1.025$ & 0.138 \\
\hline \multicolumn{7}{|l|}{ Education status } \\
\hline Middle & 3.834 & $2.099 ; 7.005$ & $<0.001$ & 0.817 & $0.305 ; 2.192$ & 0.688 \\
\hline High & 2.586 & $1.111 ; 6.022$ & $<0.001$ & 1.515 & $0.331 ; 6.936$ & 0.593 \\
\hline \multicolumn{7}{|l|}{ Income status } \\
\hline Middle & 2.625 & $1.226 ; 5.622$ & 0.013 & 0.209 & $0.065 ; 0.671$ & 0.008 \\
\hline High & 3.824 & $1.694 ; 8.628$ & 0.001 & 0.415 & $0.119 ; 1.444$ & 0.167 \\
\hline Number of children & 0.651 & $0.509 ; 0.833$ & 0.001 & 1.087 & $0.610 ; 1.936$ & 0.777 \\
\hline Total number of pregnancies & 0.758 & $0.652 ; 0.881$ & $<0.001$ & 1.171 & $0.904 ; 1.519$ & 0.232 \\
\hline Smoking & 1.990 & $1.068-3.707$ & 0.030 & 0.408 & $0.160 ; 1.041$ & 0.061 \\
\hline Alcohol use & 5.884 & $1.859 ; 18.621$ & 0.003 & 0.979 & $0.149 ; 6.849$ & 0.979 \\
\hline Diagnosis of diabetes mellitus & 0.240 & $0.083 ; 0.691$ & 0.008 & 2.482 & $0.618 ; 9.969$ & 0.200 \\
\hline Menopause year & 0.940 & $0.890 ; 0.992$ & 0.023 & 1.033 & $0.937 ; 1.138$ & 0.516 \\
\hline \multicolumn{7}{|l|}{ Birth shape } \\
\hline Caesarean & 2.877 & $1.374 ; 6.026$ & 0.005 & 0.724 & $0.231 ; 2.268$ & 0.579 \\
\hline Normal and caesarean & 1.250 & $0.529 ; 2.952$ & 0.610 & 0.455 & $0.110 ; 1.886$ & 0.278 \\
\hline Diagnosis of incontinence & 0.288 & $0.136 ; 0.609$ & 0.001 & 2.789 & $0.970 ; 8.017$ & 0.057 \\
\hline Body mass index & 0.834 & $0.778 ; 0.893$ & $<0.001$ & 1.115 & $1.014 ; 1.226$ & 0.024 \\
\hline Total sleep duration & 1.263 & $1.063 ; 1.500$ & 0.008 & 0.878 & $0.657 ; 1.174$ & 0.381 \\
\hline Vitamine D level & 1.048 & $1.027 ; 1.069$ & $<0.001$ & 0.963 & $0.941 ; 0.987$ & 0.002 \\
\hline MRS Somatic subscales & 0.698 & $0.624 ; 0.780$ & $<0.001$ & 1.274 & $1.087 ; 1.494$ & 0.003 \\
\hline MRS Psychological subscales & 0.742 & $0.669 ; 0.823$ & $<0.001$ & 0.958 & $0.799 ; 1.148$ & 0.641 \\
\hline MRS Urogenital subscales & 0.511 & $0.426 ; 0.612$ & $<0.001$ & 1.670 & $1.326 ; 2.102$ & $<0.001$ \\
\hline
\end{tabular}

$\beta=$ Regression coefficient 
In this study, higher vitamin $D$ levels were negatively correlated with the severity of menopausal symptoms. Villa and Bove reported that individuals with lower levels of vitamin $D$ presented more severe symptoms of menopause. ${ }^{11,12}$ The sufficient level of vitamin $D$ can decrease the severity of menopausal symptoms by decreasing the bodily pain of menapausal women, preserving the serotonin levels, and relieving vasomotor symptoms.

In this study, presence of chronic diseases were related with increased severity of menopausal symptoms and this finding is in concordance with other study findings. ${ }^{13,14}$ As the number and presence of chronic disease increase, the severity of menopausal symptoms increase because of the addition of symptoms associated with these additional diseases.

According to this research, individuals that were experiencing chronic bodily pain, short sleep time, and dissatisfied from sex had higher scores of postmenopausal symptoms. As a result of decrease in the level of estrogen during menopause, women can experience bodily pain, urogenital complaints, and sleep problems. ${ }^{15}$ Because these complaints are part of menopause, post-menopausal symptoms scores may be high.

The frequency of sexual function disorders in his study was $76.9 \%$. The prevalence of sexual function disorder among Turkish women was reported as $85.9 \%$, according to a research conducted in Turkey. ${ }^{16}$ Other research from Spain and Korea reported the prevalence of sexual dysfunction as $64 \%$ and $72 \%$, respectively. 17,18 The prevalence rates vary between $25 \%$ and $63 \%$ in United States of America. ${ }^{19}$ Vaginal atrophy occurs because of hormonal, physiological changes and a decrease in lubrication which might cause sexual function disorder, a common condition in women during menopause. It is important to understand the factors other than hormonal changes for the solution to this problem that negatively affects the lives of women. The rapid decrease in the level of vitamin $D$ together with menopause may increase the prevalence and severity of sexual function disorders.

It was found in this study that a high level of vitamin D reduced the risk of sexual dysfunction. Although the number of studies conducted in this issue is limited, Krysiak et al. reported that vitamin $\mathrm{D}$ deficiency was associated with poorer sexual performance. ${ }^{6}$ Similarly, a study which was conducted among Turkish women by Canat et al. found that the higher levels of vitamin D was correlated with better sexual function. 20 It is emphasised that vitamin $D$ deficiency negatively affects sexual function by decreasing the production of endothelial nitric oxide, by decreasing the production of hormones associated with testosterone, or by increasing depressive moods. ${ }^{6}$ For these reasons, vitamin $D$ may be beneficial to prevent sexual dysfunction in menopause.
According to this research, those who have middle income level had better sexual function than those who have low income. In a study conducted in Turkey, Verit et al. argued that income and sexual function were inversely correlated. ${ }^{16}$ As the income level increases, the sexual functions of the patients may be affected by changing their living conditions, stress levels etc. The direction of the relationship between income and sexual health has not been fully elucidated.

According to the findings, the authors found a negative relationship between the menopausal symptoms and sexual functions. Llaneze et al. supported the conclusion in their study that sexual function worsens with the increase in severity of menopausal symptoms. ${ }^{17} \mathrm{~A}$ study conducted by Kokcu and Andaç among Turkish population concluded that the sexual function worsened by the increasing number of symptoms associated with menopause. 21,22 It is known that the sexual functions of women in menopause worsen with the atrophic changes in the urogenital system that form together with estrogen deficiency. 6 So sexual function disorders can be accepted as a symptom of menopause.

Although study was conducted in Izmir, Turkey's third largest city, the results of the study cannot be generalised in Turkey as the data was collected from a single city. Conducting similar studies in different cultural and climate cities can help clarify the effect of vitamin $D$ on sexual function and menopausal symptoms. Another limitation of the study is that there is no specific vitamin $D$ cut-off value for the Turkish population. If special vitamin $D$ cut-off values can be determined for Turkish population, the effect of vitamin $D$ on menopause symptoms and sexual function can be evaluated better.

\section{CONCLUSION}

High vitamin D levels may reduce menopausal symptoms and positively affect sexual function. Vitamin D value should be measured in all menopausal women and vitamin $D$ replacement may be given to women to reduce menopause-related symptoms and improve sexual function.

\section{ACKNOWLEDGMENT:}

The authors would like to thank the Izmir Katip Celebi University Scientific Research Projects Unit for providing the necessary funds for the study.

\section{ETHICAL APPROVAL:}

The ethical approval of this study was received with decision No.155 (date 17.11.2016) from the Izmir Katip Celebi University, Faculty of Medicine, Clinical Research Ethics Committee.

\section{CONFLICT OF INTEREST:}

Authors declared no conflict of interest. 


\section{AUTHORS' CONTRIBUTION:}

MA: Conception, design, data collection and/or processing, analysis and/or interpretation, literature review, writer.

EMK: Design, supervision, analysis and/or interpretation, literature review, critical review.

MS: Supervision, fundings, materials, critical review.

SA: Fundings, materials, literature review, critical review.

SA: Design, materials, data collection and/or processing, literature.

KS: Design, supervision, analysis and/or interpretation, critical review.

\section{REFERENCES}

1. Roberts $\mathrm{H}$, Hickey M. Managing the menopause: An update. Maturitas 2016; 86:53-8.

2. Kaunitz AM, Manson JE. Management of menopausal symptoms. Obstet Gynecol 2015; 126:859-76.

3. Caruso S, Rapisarda AMC, Cianci S. Sexuality in menopausal women. Curr Opin Psychiatry 2016; 29:323-30.

4. Snijder MB, van Dam RM, Visser M, Deeg DJ, Dekker JM, Bouter LM, et al. Adiposity in relation to vitamin $D$ status and parathyroid hormone levels: A population-based study in older men and women. J Clin Endocrinol Metab 2005; 90:4119-23.

5. Lerchbaum E. Vitamin D and menopause - A narrative review. Maturitas 2014; 79:3-7.

6. Krysiak R, Gilowska M, Okopien B. Sexual function and depressive symptoms in young women with low vitamin $D$ status: A pilot study. Eur J Obstet Gynecol Reprod Biol 2016; 204:108-12.

7. Gurkan CO. The validity and reliability of Turkish version of menopause rating scale. Nurs Forum $J$ 2005; 3:30-5.

8. Oksuz E, Malhan S. Reliability and validity of the female sexual function index in Turkish population. Sendrom 2005; 17:54-60.

9. Yikilkan H, Aypak C, Gorpelioglu S, Dicle M, Önder O. Parathyroid hormone and optimal vitamin D status in postmenopausal women. Turkish J Med Sci 2013; 43:990-4.

10. Van Schoor NM, Lips P. Worldwide vitamin D status. Best Pract Res Clin Endocrinol Metab 2011; 25:671-80.

11. Villa P, Amar ID, Bottoni C, Cipolla C, Dinoi G, Moruzzi MC, et al. The impact of combined nutraceutical supplementation on quality of life and metabolic changes during the menopausal transition: A pilot randomized trial. Arch Gynecol Obstet 2017; 296:791-801.

12. Bove R, Secor E, Chibnik LB, Barnes LL, Schneider JA, Bennett DA, et al. Age at surgical menopause influences cognitive decline and Alzheimer pathology in older women. Neurology 2014; 82:222-9.

13. Park SK, Harlow SD, Zheng $H$, Karvonen-Gutierrez $C$, Thurston RC, Ruppert K, et al. Association between changes in oestradiol and follicle-stimulating hormone levels during the menopausal transition and risk of diabetes. Diabet Med 2017; 34:531-8.

14. Biglia N, Cagnacci A, Gambacciani M, Lello S, Maffei S, Nappi RE. Vasomotor symptoms in menopause: A biomarker of cardiovascular disease risk and other chronic diseases? Climacteric 2017; 20:306-12.

15. Erekson EA, Li FY, Martin DK, Fried TR. Vulvovaginal symptoms prevalence in postmenopausal women and relationship to other menopausal symptoms and pelvic floor disorders. Menopause 2016; 23:368-75.

16. Verit FF, Verit A, Billurcu N. Low sexual function and its associated risk factors in pre- and post-menopausal women without clinically significant depression. Maturitas 2009; 64: 38-42.

17. Llaneza P, Fernández-Iñarrea JM, Arnott B, García-Portilla MP, Chedraui P, Pérez-López FR. Sexual function assessment in postmenopausal women with the 14-item changes in sexual functioning questionnaire. J Sex Med 2011; 8:2144-51.

18. Lindau ST, Schumm PL, Laumann EO, Levinson W, O'Muircheartaigh CA, Waite LJ. A study of sexuality and health among older adults in the United States. N Engl J Med 2007; 357:762-74.

19. Shin H, Min B, Park J, Son H. A 10-year interval study to compare the prevalence and risk factors of female sexual dysfunction in Korea: The Korean internet sexuality survey (KISS) 2014. Int J Impot Res 2017; 29:49-53.

20. Canat M, Canat L, Yener F, Hatice Ö. Vitamin D 3 deficiency is associated with female sexual dysfunction in premenopausal women. Int Urol Nephrol 2016; 48:1789-95.

21. Kokcu A, Cetinkaya MB. The effect of menopause on sexual activity. Sendrom 2004; 16:43-7

22. Andac T, Aslan E. Sexual life of women in the climacterium: A community-based study. Health Care Women Int 2017; 38: 1344-55. 